\title{
La comprensión sistémica de la educación. Una vía para políticas educativas más relevantes
}

\author{
The systemic understanding of education. \\ A pathway for most relevant educational policies
}

La educación abarca muchos aspectos y no se reduce solo al aprendizaje de competencias. Al acotar el tema al ámbito del sistema educativo nacional, y a la escuela en particular, el logro educativo del alumnado toma especial relevancia, es decir, para la mayoría de los y las alumnas de educación obligatoria, la escuela es el lugar privilegiado para adquirir las competencias básicas para la vida. No obstante, el logro educativo no depende solo de lo que haga el sistema educativo en su conjunto, pues hay muchos factores que salen de su zona de intervención.

Ahora bien, el aprendizaje del alumnado en la escuela depende de varios factores, y cada uno de ellos tiene sus características, también existen relaciones entre los factores, y estas tienen, a su vez, nuevas características. En general, los factores intervinientes en el aprendizaje del alumnado, y que han sido identificados y estudiados en la investigación educativa son: el contexto social y familiar, las reglas y recursos educativos que las autoridades educativas disponen, la escuela y el aula. A continuación se describirá cada uno de ellos y su relación con otros factores, a fin de mostrar la complejidad y también de apuntar a ciertos ajustes necesarios.

\section{EL CONTEXTO FAMILIAR Y SOCIAL}

El contexto familiar es un factor que se mide típicamente mediante encuestas donde se recoge información sobre las condiciones socioeconómicas de las familias, como: ingresos, nivel de escolaridad de los familiares cercanos (madre y padre), tamaño de la familia, condiciones físicas de la vivienda, existencia de electrodomésticos, número de bienes culturales (libros, computadora, Internet, entre otros). 
A su vez, el contexto social son mediciones de agregación estadística de información a nivel geográfico y permite caracterizar las condiciones sociales y económicas de la localidad donde se ubica la escuela (y dependiendo de la información, la agregación geográfica puede hacerse a nivel municipal, regional estatal; incluso hay estudios comparativos a nivel internacional). Según el tipo de información que se use, se puede construir información más compleja como la distribución del ingreso, índices de desarrollo humano, índices de pobreza, entre otros.

Ahora bien, según múltiples estudios desde mediados del siglo XX, el contexto social y familiar resulta el más importante predictor del aprendizaje. De los resultados de los primeros estudios se deducía el determinismo social de las condiciones de base del alumnado en su trayectoria escolar (y su impacto en el bienestar posterior de esas personas). El sentido del determinismo es que el alumnado que proviene de condiciones familiares de pobreza y bajo capital cultural tiene alta probabilidad de aprender poco o nada (incluso está el indicador de rezago educativo, que demuestra que es en las zonas más pobres de México donde existe la mayor inasistencia o abandono escolar). Un corolario que se desprende de la gran incidencia de las condiciones familiares y sociales es el bajo peso estadístico que la escuela tenía a la hora de explicar el aprendizaje. Esto ha ido cambiando con el tiempo, pues se han hecho estudios que dan cuenta de la incidencia de otros factores.

\section{LOS RECURSOS EDUCATIVOS Y REGLAS DE LAS AUTORIDADES EDUCATIVAS}

Estas se refieren a una serie de formas de intervención de las autoridades para incidir en el aprendizaje. Entre los recursos educativos tenemos: currículo, materiales educativos, la formación inicial y continua del magisterio, la infraestructura y dotación de las escuelas y el sistema de acompańamiento a las mismas. Dentro de las reglas está la forma de contratación, promoción, reconocimiento y permanencia del personal docente y directivo (directores/as de escuela, supervisores, jefes de sector), la asignación de recursos entre los distintos niveles de gobierno y las escuelas, 
entre otras. El magisterio (docentes frente a grupos, cuerpo directivo escolar y de supervisión) tiene la característica de ser el principal recurso humano del sistema educativo y sobre el que recae buena parte de las reglas formales; en este ámbito suele buscarse información acerca de su formación inicial y continua, su experiencia, entre otras.

En general, los estudios a nivel escolar han mostrado que la incidencia de los recursos educativos depende de dos condiciones: la disponibilidad y uso de los mismos. Por ejemplo, la política de libro de texto gratuito para todo el alumnado tiene incidencia en relación con si este realmente los recibe en tiempo y forma, y si su uso en el aula es pedagógicamente adecuado; lo mismo sucede con la infraestructura o la dotación de mobiliario a las escuelas.

Los resultados de las evaluaciones que se ocupan de este factor muestran que hay una concurrencia geográfica de falta, demora o mal estado de los recursos educativos en las escuelas ubicadas en zonas urbano-marginales, rurales, o que atienden a indígenas.

En cuanto a la asignación del magisterio, es habitual que los y las maestras de recién ingreso a la profesión sean asignadas a escuelas ubicadas en estas mismas zonas. También existen resultados que muestran que el ausentismo docente es más intenso en las escuelas antes mencionadas.

\section{LA ESCUELA}

El factor escuela está compuesto de varios elementos, dentro de los cuales se destacan: la función directiva, las condiciones básicas de enseñanza y aprendizaje (que son recursos de los que proveen las autoridades, pero que en México se transforman cada vez más en recursos financieros que se transfieren a las escuelas para que estas los usen con base en sus necesidades educativas). La función directiva consiste en la gestión y coordinación de lo que acontece con familiares, docentes y alumnado. Contiene la complejidad de la gestión escolar (más administrativa y de relación con las autoridades educativas, pues es su emisario en la escuela) y la de liderazgo educativo (más pedagógica y de participación con los y las docentes, alumnado y familiares -es su emisario ante las autoridades educativas-). Algunos de los temas abordados en la ges- 
tión escolar son: dirección escolar (liderazgo, clima de confianza, decisiones compartidas, planeación institucional, comunicación, redes), desempeño del cuerpo docente (mejora continua, planeación pedagógica), gestión del aprendizaje, gestión de los órganos de apoyo escolar (Consejo técnico, Consejo de participación social), relación con los familiares; también el tema de la carga administrativa (tanto para maestros/as frente a grupo como para personal directivo y mesoestructura).

Ahora bien, el factor escuela tiene incidencia en el aprendizaje. La investigación ha dado cuenta de la relación positiva entre una escuela con buenos resultados en aprendizaje respecto a buenos indicadores de gestión escolar, liderazgo educativo y participación activa de los familiares. También sucede al contrario: una escuela de "baja intensidad" tiene poca incidencia en los aprendizajes generales de su alumnado. Hay tendencias de segregación educativa por el origen social del alumnado, resultado que atestigua que la escuela no es una institución aislada y que hay dinámicas sociales que le afectan ostensiblemente.

Y dado que la escuela no está aislada, se puede decir que tiene factores exógenos (sociales, familiares, de relación con las autoridades) que intervienen en su desempeño. Al mismo tiempo, también hay evidencia de que esos factores exógenos pueden ser contrarrestados, en cierta medida, mediante una buena conjunción de los factores endógenos.

\section{EL AULA}

El factor aula tiene tres elementos: docente, alumnado y condiciones de aula. Dentro de las características del cuerpo docente (su práctica y desempeńo en aula), se encuentran: compromiso y expectativas por el aprendizaje, planeación didáctica, ambiente de aula, gestión curricular, gestión didáctica y evaluación. A su vez, entre las características del alumnado están sus condiciones familiares (hábitos saludables, ambiente familiar, capital cultural, trayectoria académica), condiciones personales (estilos de aprendizaje, interés, carácter, educación emocional...). Por último, están las condiciones de aula: recursos didácticos, mobiliario, tecnología para el aprendizaje, ruido, clima, entre otras. 
La investigación y la evaluación educativa cada vez dan más cuenta de la injerencia del cuerpo docente en el aprendizaje, a tal punto que, de manera equivocada, se les ha ido atribuyendo toda la responsabilidad del aprendizaje, tal como sucede en la Ley General del Servicio Profesional Docente. Esto es erróneo, no solo porque, como hemos visto, el aprendizaje depende de otros factores simultáneamente, sino porque hay interrelación entre los factores; por ejemplo, una docente no trabaja aislada, lo hace en una escuela, y la forma como la escuela sea gestionada y liderada posibilita o constriñe su desempeño. No obstante, el factor docente cuenta: los y las maestras pueden y hacen diferencia.

Por su parte, las características de los alumnos también intervienen. Una de ellas, que ha sido documentada sistemáticamente, es el sexo. De manera reiterada los resultados en las evaluaciones de aprendizaje de matemáticas muestran que los hombres obtienen puntajes más altos, mientras que las mujeres lo hacen en lenguaje y comunicación. No hay evidencia de que esto tenga orígenes biológicos, lo cual se traduce en que obedece al nivel relacional docente-alumno/a. Las investigaciones muestran que las expectativas y la forma de trato e interlocución del profesorado con las alumnas o alumnos marcan tendencia. También la sociedad marca roles, que implican que las mujeres se relacionen de manera distinta de los hombres en la escuela y el aula: por ejemplo, las niñas en los recreos tienden a estar en grupos conversando, mientras los niños desarrollan actividad física, y esto es asumido como normal por parte del profesorado. Otras variables relevantes son si un alumno/a llega bien alimentado y descansado o no a la escuela, la distancia que tiene que caminar o si llega en transporte.

Por último, están las condiciones físicas y de dotación del aula. Hay una tendencia positiva en el hecho de tener disponible y en uso ciertos recursos y materiales didácticos ${ }^{1}$ y un mejor logro en aprendizajes. Como hemos visto, la disponibilidad puede

\footnotetext{
${ }^{1}$ No todos ellos han de ser dotados por agentes externos, pues en varios modelos educativos (como el Programa de Aprendizaje Multigrado en Puebla) alumnado, profesorado y familiares participan en el diseño y elaboración de diferentes materiales educativos (como rincones de aprendizaje, croquis de la localidad, entre otros.
} 
o no depender de la escuela y el aula, pero lo que sí depende de estas es su uso.

\section{COROLARIO}

La mejora de la calidad de la educación es un asunto de suma complejidad. Requiere que las políticas públicas sean equitativas, pertinentes, relevantes, eficaces y eficientes y esto es así tanto para las educativas, como para otras que vayan a contribuir a la disminución de las disparidades sociales, culturales y económicas. Así se contribuye a satisfacer los derechos humanos y sociales que merece la población.

Dentro de las políticas educativas es imperioso que se atiendan los factores más influyentes, hay que cambiar las reglas institucionales (formales e informales) de exclusión en la distribución de los recursos educativos, emprender políticas y programas que transformen los procesos y culturas escolares y áulicas con determinación, audacia y prontitud, todo dentro de un ambiente de respeto, diálogo y participación del magisterio (entendido como sus actores, y no solo mediados por sus organizaciones sindicales). Puede que las reformas sin las y los maestros sigan los caminos normativos y legales, pero contar con ellas y ellos asegura que llegarán a las escuelas y las aulas.

A su vez, las políticas educativas han de seguir la lógica propia de lo educativo: el aprendizaje ocurre en, desde y con el/la aprendiz. Por ejemplo, la evaluación del magisterio debiera servir para que ellas y ellos aprendan de los resultados, puedan transformar sus deficiencias y potenciar sus fortalezas. En este sentido la evaluación del desempeño docente deberá ser pertinente y relevante, lo cual implica tener perfiles, indicadores y parámetros que lean lo que hacen los y las maestras, con especial énfasis en el aula (aunque no solo, pues su participación en colegiados escolares y otros asuntos están dentro de su horizonte de trabajo). Para leer el aula se requiere de instrumentos especialmente elaborados con este fin, que además incluyan, en el proceso de evaluación: las etapas de mejora continua de su práctica.

Igualmente, es muy importante que las autoridades educativas (federales y estatales) tengan en cuenta la complejidad propia 
del sistema y así distingan los factores exógenos de los endógenos al mismo y a la escuela. En cuanto a lo factores endógenos, es especialmente importante que no atribuyan toda la responsabilidad del aprendizaje a los y las maestras, tal como se está haciendo en la actualidad. La evaluación al magisterio deberá tener un énfasis más formativo. $\mathrm{Y}$ no basta con responder mediante cursos de actualización diseñados para atender a las y los maestros con bajos puntajes en las evaluaciones de desempeño. Una característica importante de la profesión docente es que su saber implica la socialización y por ello el trabajo entre pares en las propias escuelas es clave.

Por último, es importante decir que la mayoría de la investigación educativa atiende por separado los factores, e incluso atiende elementos particulares. Bien vendría hacer evaluaciones más comprensivas, más ahora que el Instituto Nacional para la Evaluación de la Educación (INEE) cuenta con autonomía sectorial e incremento en sus recursos. Esto incluye incorporar elementos más propios del alumnado, como evaluar su educación socioemocional, su desarrollo ético y otros aspectos, algunos de ellos, todavía del currículo oculto de las escuelas y las aulas. 
